\title{
Relationship of Occlusal Schemes with the Occurrence of Temporomandibular Disorders
}

\author{
Dina H. Sugiaman', Laura S. Himawan², Sitti Fardaniah ${ }^{2}$ \\ ${ }^{1}$ Prosthodontics Residency Program, Faculty of Dentistry, Universitas Indonesia, Jakarta 10430, Indonesia \\ ${ }^{2}$ Department of Prosthodontics, Faculty of Dentistry, Universitas Indonesia, Jakarta 10430, Indonesia \\ Correspondence e-mail to: bicuspid_dhi@yahoo.com
}

\begin{abstract}
Masticatory system is a complex functional unit of the body primarily responsible for mastication, speech and deglutition process. Temporomandibular disorders (TMD) is used to describe all functional disturbances of the masticatory system. The etiology of TMD is multifactorial, such as occlusal disharmony and emotional stress. The relationship between occlusion and TMD has been highly debated in dentistry, one of the occlusal factors is the occlusal schemes. Occlusal schemes are defined as bilateral canine guidance, unilateral canine guidance, group function, and balanced occlusion. However, studies about the relationship of occlusal schemes and the occurrence of the TMD are still limited and remained controversial. Objective: To investigate the relationship of occlusal schemes with the occurrence of TMD. Methods: A cross-sectional study was conducted at the Faculty of Dentistry, Universitas Indonesia. A total of 127 students were included in this study. Subjects were examined based on Clinical Helkimo Index and divided into TMD and non-TMD groups. Subjects were categorized as non-TMD group if the value of clinical Helkimo index was 0 and as TMD group when the value ranged between 1-25. Results: Balanced occlusion schemes has a greater risk of TMD occurrence with odds ratio value of 5.6 and $95 \%$ confidence interval of 1.188 to $26.331(p=0.021)$. Conclusion: Balanced occlusion has a significant relationship with the occurrence of TMD.
\end{abstract}

\begin{abstract}
ABSTRAK
Hubungan skema oklusal dengan terjadinya kelainan temporomandibula. Sistem mastikasi merupakan unit kompleks fungsional tubuh yang bertanggung jawab untuk pengunyahan, bicara, dan proses deglutasi. Temporomandibular Disorders (TMD) digunakan untuk menggambarkan semua gangguan fungsional dari sistem mastikasi. Etiologi TMD bisa disebabkan berbagai faktor, seperti ketidakharmonisan oklusal dan stres emosional. Hubungan antara oklusi dan TMD diperdebatkan dalam kedokteran gigi, salah satu faktor oklusal adalah skema oklusal. Skema oklusal didefinisikan sebagai panduan kaninus bilateral, panduan kaninus unilateral, fungsi kelompok, dan oklusi seimbang. Namun, studi tentang hubungan skema oklusal dan terjadinya TMD masih terbatas dan tetap kontroversial. Tujuan: Untuk menyelidiki hubungan skema oklusal dengan terjadinya TMD. Metode: Studi potong lintang dilaksanakan di Fakultas Kedokteran Gigi, Universitas Indonesia. Subjek penelitian berjumlah 127 mahasiswa. Subjek diperiksa berdasarkan Indeks Klinis Helkimo dan dibagi menjadi kelompok TMD dan non TMD. Subjek dikategorikan sebagai kelompok non-TMD jika nilai Indeks Klinis Helkimo bernilai 0 dan kelompok TMD jika nilainya antara 1-25. Hasil: Skema oklusi yang seimbang memiliki risiko yang lebih besar untuk terjadinya TMD dengan nilai odd ratio 5,6 dengan confidence interval 95\% 1,188-26,331 $(p=0,021)$. Simpulan: Oklusi yang seimbang mempunyai hubungan signifikan dengan terjadinya TMD.
\end{abstract}

Key words: occlusal schemes, temporomandibular disorders

\section{PENDAHULUAN}

Okeson menggunakan istilah temporomandibular disorders (TMDs) untuk seluruh gangguan fungsional dalam sistem pengunyahan. Etiologi gangguan sendi temporomandibula adalah faktor-faktor yang dapat menimbulkan pembebanan yang melebihi kapasitas adaptasi sendi, baik beban sesaat yang ekstrim maupun beban berulang. Umumnya ditandai oleh rasa nyeri pada otot-otot mastikasi dan sendi saat palpasi, 
keterbatasan gerak mandibula dan bunyi sendi. Rasa sakitnya tidak berhubungan dengan sakit gigi. ${ }^{1-3}$

Faktor yang paling sering dihubungkan dengan terjadinya gangguan sendi temporomandibula adalah oklusi yang tidak baik dan stres emosional. Hubungan antara faktor oklusi dan gangguan sendi temporomandibula sulit dipahami dan hingga saat ini masih merupakan hal yang diperdebatkan dalam bidang kedokteran gigi. Beberapa parameter oklusal seperti tipe oklusi, tipe skema oklusi, kontak pada sisi keseimbangan, dan parameter okusal lainnya sering kali dikatakan sebagai penyebab terjadinya gangguan sendi temporomandibula, namun teori-teori yang mendukung hal tersebut masih terbatas dan masih kontroversial. $^{4-7}$

Salah satu parameter yang masih dipertentangkan adalah pemilihan skema oklusi khususnya dalam perawatan gigi tiruan sebagian dan gigi tiruan cekat. Pada awal abad ke-20, para peneliti meyakini bahwa balanced occlusion adalah penuntun yang paling ideal dalam pembuatan gigi tiruan, karena selain memberikan kestabilan yang terbaik bagi gigi tiruan penuh juga diharapkan dapat mendistribusikan beban secara merata ke seluruh gigi asli yang masih ada. Akan tetapi berdasarkan hasil penelitian Schuyler yang didukung oleh peneliti-peneliti lainnya, konsep balanced occlusion mulai digantikan dengan canine guidance dan group function. ${ }^{8,9}$ Canine protected occlusion seringkali dikatakan sebagai skema yang ideal karena permukaan akar gigi kaninus yang luas dan panjang, serta posisinya yang strategis jauh dari fulkrum dapat melindungi gigi posterior dari beban lateral. Akan tetapi tidak ada bukti-bukti biologis, klinis, dan histologis mengenai mekanisme proteksi gigi kaninus. Di lain pihak beberapa peneliti lainnya menyarankan group function occlusion karena selain merupakan oklusi yang paling banyak dimiliki individu terutama orang dewasa, tipe oklusi ini juga memberikan stimulasi yang lebih baik pada periodonsium, sehingga periodonsium pada kelompok ini lebih kuat meskipun terdapat resesi gingiva yang luas. ${ }^{10}$

Oklusi yang baik harus memungkinkan mandibula bertranslasi tanpa hambatan oklusal saat gerakan fungsional terutama pada segmen posterior, sehingga efisiensi pengunyahan pada sisi kerja tidak hilang, distribusi beban aksial lebih merata, dan dapat menghindari jatuhnya beban berlebih pada sendi temporomandibula. ${ }^{5}$ Oklusi sangat penting karena merupakan dasar dari fungsi mastikasi. Dalam bidang prostodontik, salah satu tujuan pembuatan gigi tiruan adalah mengembalikan fungsi. Oleh karena itu, pemahaman tentang oklusi yang baik diperlukan oleh prostodontis dapat merehabilitasi oklusi sehingga dicapai fungsi yang dinamis. . $^{1,45}$

Berdasarkan banyaknya perbedaan pendapat dan masih kurangnya penelitian mengenai hubungan antara skema oklusi terhadap terjadinya gangguan sendi temporomandibula, penulis tertarik untuk meneliti hubungan antara gangguan sendi temporomandibula dengan skema oklusi. Selain faktor oklusi, stres emosional dan parafungsi juga seringkali dihubungkan dengan terjadinya pembebanan berlebih pada sendi rahang, oleh karena itu penelitian ini juga akan membandingkan peranan skema oklusi dengan kondisi maloklusi dan parafungsi terhadap terjadinya gangguan sendi temporomandibula.

\section{METODE}

Penelitian ini merupakan penelitian potong lintang yang dilakukan di klinik Fakultas Kedokteran Gigi Universitas Indonesia. Total subjek penelitian berjumlah 127 orang dalam rentang usia 20-40 tahun. Subjek penelitian adalah individu yang tidak memiliki maupun memiliki gejala gangguan sendi temporomandibula namun tidak menyadari atau tidak mencari perawatan.

Alat ukur dalam penelitian ini adalah pemeriksaan Indeks Klinis Helkimo dan parameter oklusi serta anamnesis untuk mengetahui parafungsi. Indeks Klinis Helkimo dipilih karena terdiri dari sekumpulan pemeriksaan untuk mendeteksi tanda dan gejala TMD. Selain Indeks Klinis Helkimo, juga ditambahkan pemeriksaan terhadap klasifikasi oklusi berdasarkan klasifikasi Angel, skema oklusi, dan kebiasaan parafungsi.

Pemeriksaan skema oklusi dilakukan dengan cara menginstruksikan dan melatih pasien melakukan gerakan protrusif dan lateral yang diharapkan. Gerakan berhenti ketika gigi posterior berkontak pada posisi tonjol ketemu tonjol selama gerak lateral dan gigi anterior berkontak tepi ketemu tepi saat gerak protrusif. Dental floss dimasukkan melintasi distal gigi posterior kiri dan kanan kemudian dilewatkan di antara kontak gigi geligi untuk mengetahui gigi-gigi mana saja yang berkontak. Pemeriksaan dilakukan pada working side maupun pada balancing side.

Skema oklusi yang dipergunakan dalam penelitian ini adalah:

I : Bilateral canine protected occlusion jika hanya terdapat kontak gigi kaninus saat gerak lateral pada masing -masing sisi kerja dan pada gigi insisif sentral pada gerak protrusif sedangkan tidak terdapat kontak di oklusal gigi posterior selama gerak lateral dan protrusif;

II : Unilateral canine protected occlusion jika canine protected occlusion hanya terdapat pada salah satu gerak lateral sedangkan gerak lateral lainnya adalah group function occlusion;

III : Group function occlusion jika selama gerak 
lateral terjadi kontak antara kaninus, premolar, dan molar pada working side tanpa ada kontak di balancing side. Kontak yang hanya terjadi pada gigi kaninus dan premolar atau kontak yang hanya terjadi pada gigi molar juga dikategorikan ke dalam group function;

IV : Balanced occlusion jika selama gerak lateral terjadi kontak pada working side dan pada balancing side, baik kontak hanya beberapa gigi maupun seluruh gigi;

$\mathrm{V}$ : Oklusi lainnya jika kontak yang terjadi selain yang dikategorikan pada bilateral canine protected occlusion, unilateral canine protected occlusion, group function occlusion, maupun balanced occlusion.

\section{HASIL}

Data skema oklusi yang terkumpul menunjukkan bahwa sebagian besar subjek termasuk dalam kategori group function yaitu sebesar 58,3\%, sedangkan kategori skema oklusi lainnya berkisar antara 13,4-14,2\%. Sebagian besar subjek masuk dalam klasifikasi maloklusi kelas I yaitu sebesar $73,2 \%$, diikuti dengan klasifikasi maloklusi kelas III sebanyak $15 \%$ dan klasifikasi maloklusi kelas II sebanyak 11,8\%. Maloklusi kelas II tidak dipisahkan menjadi divisi 1 dan divisi 2 karena terdapat kelompok dengan nilai expected kurang dari 5. Subjek yang memiliki parafungsi baik berupa bruxism maupun clenching sebesar 34,6\%. Pada penelitian ini, jumlah subjek yang masuk ke dalam kriteria TMD adalah 78 orang, sehingga dapat disimpulkan bahwa prevalensi terjadinya gangguan sendi pada subjek penelitian ini adalah sebesar $61,4 \%$.

Sebagian besar skema oklusi tidak memiliki perbedaan yang besar antara jumlah subjek yang masuk dalam kriteria TMD dan jumlah subjek yang masuk dalam kriteria non-TMD kecuali pada kelompok balanced occlusion, jumlah subjek non-TMD dibandingkan dengan jumlah subjek TMD adalah 1,6 berbanding 12,6 . Hal ini berarti jumlah kelompok balanced occlusion yang masuk dalam kriteria TMD 7,9 kali lebih besar daripada non-TMD (Tabel 1). Perbandingan antara jumlah subjek TMD dengan Non TMD pada masing-masing klasifikasi oklusi tidak jauh berbeda kecuali jumlah subjek TMD pada maloklusi kelas II sebesar 9,4\% dan Non-TMD hanya sebesar 2,4\% (Tabel 1). Tidak terdapat perbedaan yang bermakna antara prevalensi subjek yang masuk ke dalam kriteria TMD dan non-TMD pada pasien yang tidak memiliki parafungsi (Tabel 1). Pada kelompok pasien yang memiliki parafungsi terjadi peningkatan jumlah subjek TMD $(24,4 \%)$ dibandingkan yang nonTMD (10,2\%).
Tabel 1. Hubungan skema oklusi, klasifikasi oklusi, dan parafungsi terhadap terjadinya gangguan sendi

\begin{tabular}{lccc}
\hline Variabel & \multicolumn{2}{c}{$\begin{array}{c}\text { Indeks Klinis } \\
\text { Helkimo }\end{array}$} & Nilai $\boldsymbol{p}$ \\
\cline { 2 - 4 } & $\begin{array}{c}\text { Non-TMD } \\
(\%)\end{array}$ & $\begin{array}{c}\text { TMD } \\
(\%)\end{array}$ & \\
\hline A. Skema oklusi & & & 0,074 \\
Bilateral Canine & 5,5 & 8,7 & \\
Unilateral Canine & 6,3 & 7,1 & \\
Group Function & 25,2 & 33,1 & \\
Balanced Occlusion & 1,6 & 12,6 & \\
B. Klasifikasi maloklusi & & & 0,288 \\
Angle Kelas I & 29,9 & 43,3 & \\
Angle Kelas II & 2,4 & 9,4 & \\
Angle Kelas III & 6,3 & 0,9 & \\
C. Parafungsi & & & 0,128 \\
Tidak ada parafungsi & 28,3 & 37 & \\
Ada parafungsi & 10,2 & 24,4 & \\
$\quad$ Total & 100 & 100 &
\end{tabular}

Tabel 2. Analisis multivariat hubungan skema oklusi dengan gangguan sendi temporomandibula dengan uji kai kuadrat

\begin{tabular}{lrrrr}
\hline & Indeks Klinis Helkimo & OR (CI 95\%) \\
\cline { 2 - 5 } & $\begin{array}{c}\text { Non TMD } \\
\text { N (\%) }\end{array}$ & TMD & N (\%) \\
\hline Skema oklusi & & Nilai $p$ & \\
Group Function & $32(25,2)$ & $42(33,1)$ & 0,130 & Pembanding \\
Bilateral canine & $7(5,5)$ & $11(8,7)$ & 0,738 & $1,197(0,420-3,502)$ \\
Unilateral canine & $8(6,3)$ & $9(7,1)$ & 0,775 & $0,722(0,265-2,287)$ \\
Balanced occlusion & $2(1,6)$ & $16(12,6)$ & $* 0,021$ & $5,594(1,188-26,331)$ \\
Total & $78(61,4)$ & $49(38,6)$ & \\
\hline
\end{tabular}

hubungan bermakna $(p<0,05)$

Hasil analisis bivariat terhadap Indeks Klinis Helkimo memperlihatkan nilai $p$ skema oklusi adalah 0,074 dan nilai $p$ parafungsi adalah 0,128 . Masing-masing nilai $<0,25$, oleh karena itu pengaruh skema oklusi dan parafungsi terhadap terjadinya gangguan sendi temporomandibula dapat dimasukkan ke dalam analisis multivariat (Tabel 2).

Faktor etiologi yang dianalisis adalah skema oklusi dan parafungsi. Pada hasil akhir, parafungsi dikeluarkan dari analisis karena nilai $p$ menunjukkan tidak ada hubungan bermakna antara parafungsi dengan terjadinya gangguan sendi temporomandibula $(p=0,196)$. Dengan demikian dapat disimpulkan bahwa skema oklusi lebih memiliki hubungan terhadap terjadinya gangguan sendi temporomandibula dibandingkan dengan parafungsi.

Hasil analisis multivariat regresi logistik memperlihatkan terdapat hubungan yang bermakna antara 
balanced occlusion untuk memiliki resiko TMD ( $p=0,021)$. Nilai odds ratio menunjukkan kemungkinan subjek yang memiliki balanced occlusion dibandingkan group function untuk beresiko TMD adalah sebesar 5,6 kali. Probabilitas subjek yang memiliki balanced occlusion untuk mengalami TMD sebesar $84,8 \%$ $(\mathrm{P}=\mathrm{OR} /(1+\mathrm{OR}))$.

\section{PEMBAHASAN}

Penelitian ini adalah penelitian analitik dengan desain potong lintang. Sampel diambil dari populasi bukan pasien berusia 18-40 tahun sehingga generalisasi cukup memadai dan cukup mewakili kelompok usia yang paling banyak mencari perawatan gangguan sendi temporomandibula. Etiologi gangguan sendi temporomandibula bersifat multifaktorial, namun dalam penelitian ini faktor-faktor yang diteliti hanyalah faktor skema oklusi, klasifikasi maloklusi, dan kebiasaan parafungsi.

Subjek harus memiliki jumlah gigi yang memungkinkan untuk menganalisis faktor-faktor oklusi oleh karena itu kehilangan gigi posterior tidak boleh lebih dari 2 gigi. Awalnya skema oklusi dikategorikan ke dalam kelompok bilateral canine guidance, unilateral canine guidance, group function, balanced occlusion dan oklusi lain-lain. Kelompok skema oklusi untuk kategori oklusi lain-lain kemudian dikeluarkan dari penelitian ini karena hanya terdiri dari 3 subjek.

Jumlah skema oklusi group function paling banyak dibandingkan skema oklusi lainnya (58,3\%). Tingginya persentase ini sesuai dengan hasil penelitian sebelumnya yang dilakukan sebelumnya yaitu group function merupakan skema oklusi yang paling banyak $(41,49 \%)$ diikuti dengan bilateral canine guidance $(26,38 \%) .{ }^{9}$ Skema oklusi group function paling banyak dimiliki populasi karena keausan fisiologis yang terjadi akibat adaptasi terhadap fungsi mastikasi.

Walaupun maloklusi sering dipertimbangkan sebagai faktor etiologi gangguan sendi temporomandibula, akan tetapi hasil penelitian klinis untuk mendukung teori tersebut masih belum jelas dan saling bertentangan. Beberapa penelitian mengatakan bahwa maloklusi dapat menyebabkan terjadinya gangguan sendi temporomandibula, khususnya maloklusi kelas II. Penelitian yang mengatakan maloklusi kelas II divisi 1 berpeluang mempengaruhi terjadinya gangguan sendi karena jarak horizontal yang besar menyebabkan peningkatan jumlah skema oklusi balanced occlusion. ${ }^{11}$ Jarak horisontal yang besar juga menyebabkan individu cenderung untuk memajukan mandibula ke anterior untuk mendapatkan estetik yang lebih baik atau untuk memotong di anterior sehingga jika hal ini terjadi dalam waktu yang lama akan menyebabkan kelelahan pada otot mastikasi dan ligamen kolateral.
Deskripsi data Indeks Klinis Helkimo pada penelitian ini juga menunjukkan kelompok maloklusi kelas II memiliki kecenderungan mengalami TMD dibandingkan maloklusi lainnya. Nilai kemaknaannya lebih besar dari 0,25 sehingga tidak dapat dilanjutkan ke dalam analisis multivariat. Beberapa penelitian yang telah dilakukan sebelumnya juga tidak menemukan hubungan yang bermakna antara gangguan sendi dengan faktor maloklusi. Besar kemungkinan faktor oklusi yang lebih berperan adalah faktor yang menyebabkan aktivitas otot berlebih atau tidak seimbang seperti adanya blocking, occlusal interference, kontak asimetris, kontak prematur, atau gigitan silang satu sisi. Kemungkinan lain penyebab hubungan yang tidak bermakna antara maloklusi kelas II dengan terjadinya gangguan sendi adalah jumlah kelompok maloklusi kelas II dalam penelitian ini sangat sedikit.

Hasil analisis bivariat antara parafungsi dan gangguan sendi berdasarkan Indeks Klinis Helkimo memperlihatkan pasien yang tidak memiliki kebiasaan parafungsi memiliki peluang yang hampir sama untuk tidak mengalami maupun mengalami gangguan sendi temporomandibula. Hal ini menunjukkan bahwa selain parafungsi terdapat faktor lain yang berperan terhadap terjadinya gangguan sendi. Pada kelompok sampel yang memiliki kebiasaan parafungsi terjadi peningkatan jumlah subjek yang mengalami gangguan sendi temporomandibula sebanyak dua kali lebih besar.

Prevalensi terjadinya gangguan sendi pada populasi mahasiswa FKG UI adalah sebesar $62,3 \%$. Hasil ini serupa dengan hasil penelitian sebelumnya yang memperlihatkan sebanyak $66,67 \%$ subjek memiliki gangguan fungsi sendi temporomandibula mulai dari ringan hingga berat berdasarkan Indeks Helkimo klinis pada populasi mahasiswa FKG UI. ${ }^{12}$ Kemungkinan subjek yang memiliki balanced occlusion dibandingkan group function untuk berisiko mengalami TMD adalah sebesar 5,6 kali (OR). Hasil ini sesuai dengan hasil deskripsi Indeks Klinis Helkimo dengan terlihatnya peningkatan gangguan sendi pada skema oklusi balanced occlusion. Kontak yang terus menerus pada balanced occlusion menyebabkan proses keausan meningkat, terjadi kerusakan jaringan periodontal dan trauma mikro pada sendi rahang dan timbul disfungsi sendi seperti penyimpangan gerak rahang, keterbatasan gerak, serta bunyi dan nyeri sendi.

Tidak terdapat perbedaan yang bermakna antara bilateral canine guidance dan unilateral canine guidance untuk mengalami gangguan sendi dibandingkan group function. Oleh karena itu, sebaiknya rehabilitasi oklusi lebih dititikberatkan pada kesehatan dan fungsi sistem mastikasi daripada mengacu pada konfigurasi oklusal tertentu. Baik group function maupun canine guidance dapat dianggap sebagai kondisi fisiologis selama rahang dapat berfungsi efisien tanpa adanya kondisi patologis 
sehingga tidak perlu untuk mengubah skema oklusi ke kondisi tertentu. Jika terdapat kondisi patologis yang membutuhkan rehabilitasi, perlu dilakukan beberapa pertimbangan dari berbagai aspek untuk memilih antara canine guidance atau group function.

Walaupun restorasi cekat terletak pada gigi kaninus, konsep canine guidance dapat diterapkan dengan syarat jaringan periodontal dan rasio mahkota akar gigi tersebut masih baik, jenis bahan bahan restorasi yang dipilih harus cukup kuat untuk menerima beban, dan sisa jaringan gigi penyangga yang dipreparasi masih cukup banyak. Pada pembuatan gigi tiruan sebagian lepas, konsep anterior guidance juga dapat diterapkan sesuai dengan kondisi jaringan periodontal gigi geligi yang masih ada. Balanced occlusion tetap merupakan skema oklusi yang paling dapat memberikan kestabilan yang terbaik bagi gigi tiruan penuh terutama jika telah terjadi resorbsi tulang alveolar yang besar. Beberapa klinisi menerapkan konsep anterior guidance pada gigi tiruan penuh dengan pertimbangan untuk mendapatkan estetika yang maksimal, akan tetapi ketinggian tulang alveolar harus cukup sehingga kestabilan dan retensi dapat diperoleh dari jaringan pendukung yang masih ada.

\section{SIMPULAN}

Terdapat hubungan antara skema oklusi tipe balanced occlusion dengan terjadinya gangguan sendi temporomandibula, namun tidak tipe lainnya. Skema oklusi tipe balanced occlusion juga lebih berperan terhadap terjadinya gangguan sendi temporomandibula dibandingkan parafungsi dan maloklusi. Konsep oklusi dinamis sebaiknya menitikberatkan pada kesehatan dan fungsi sistem mastikasi, bukan pada konfigurasi oklusal tertentu. Oleh karena itu, tidak diindikasikan untuk mengubah oklusi. Dalam bidang prostodonti dan orthodonti, sering kali ditemukan kasus kehilangan gigi disertai hilangnya skema oklusi atau kasus di mana oklusi yang ada menyebabkan kondisi patologis sehingga membutuhkan rehabilitasi. Ketika harus memperbaiki atau mengubahanterior guidance, prostodontis dan ortodontis perlu melakukan beberapa pertimbangan dari berbagai aspek sebelum memilih antara canine guidance atau group function.

\section{DAFTAR PUSTAKA}

1. Okeson JP. Management temporomandibular disorders and occlusion. 6th ed, St. Louis, Mosby. 2008.

2. McNeil C. Temporomandibular Disorders: Guideline for Classification, Assessment and Management. 2nd ed. Quintessence Pub Co., Illinois, USA. 1993.

3. Clark GT, Delcanho RE, dan Goulet JP. The utility and validity of current diagnostic procedures for defining temporomandibular disorders patients. Adv Dent Res. 1993;7:97-112.

4. Klineberg I, Jagger R. Occlusion and clinical practice an evidence - based approach. London, Wright. 2004.

5. Dawson PE. Functional occlusion: from TMJ to smile design. Mosby, Florida, Elsevier. 2007.

6. Dawson J. New definition for relating occlusion to varying conditions of the temporomandibular joint. J Prosthet Dent. 1995;74:619-27.

7. Bonjardim LR, Gavião MB, Pereira LJ, Castelo PM, Garcia RC. Sign and symptoms of TMD in adolescents. Braz Oral Res. 2005;19:93-8.

8. Thornton LJ. Anterior guidance: group function/ canine guidance. A literature review. J Prosthet Dent. 1990;64:479-82.

9. Panek H, Brozowska TM, Nowakowska D, Bielicki G, Mankiewicz M. Dynamic occlusion in natural permanent dentition. Quintessence Int. 2008;39:337-42.

10. Williamson EH, Lundgyuist DO. Anterior guidance: It's effect on electromyographic actifity of the temporal and masseter muscles. J Prosthet Dent. 1983;49:816-23.

11. Al-Hadi A. Prevalence of temporomandibular disorders in relation to some occlusal parameters. J Prosthet Dent. 1993;70:345-50.

12. Indrawati L. Nilai titik potong indeks diagnostic gangguan sendi temporomandibula sebagai alat skrining gangguan sendi temporomandibula. Universitas Indonesia, Fakultas Kedokteran Gigi, Tesis. 2008. Indonesian.

13. Standlee JP, Caputo AA, Ralph JP. Stress transfer to the mandible during anterior guidance and group function eccentric movements. J Prosthet Dent. 1979;41:35-9. 